\title{
How to Deliver the Necessary Data about Serious Injuries to the European Union
}

\author{
Péter Holló ${ }^{1,2}$ and Diána Sarolta Kiss ${ }^{1}$ \\ 1. Department of Transport, Széchenyi István University, Györ 9026, Hungary \\ 2. KTI Institute for Transport Sciences Non-Profit Ltd., Budapest 1119, Hungary
}

\begin{abstract}
In the EU (European Union) in 2011, the number of the serious road injuries was more than 250,000 and the death tolls were 28,000. In the last period (between 2001 and 2011), the number of those who lost their lives as a result of road accident decreased ordinarily by $43 \%$ in the EU countries on average, whereas that of the seriously injured by $36 \%$-in the light of these countries' own definitions differing from one another. The "MAIS $3+$ " is the adopted common EU definition, that is all Grade- 3 or above values according to the MAIS (maximum abbreviated injury scale). Although the definition seems professionally justified, further clarification is necessary in our view. For the years 2014 and 2015, the EU has already drawn up specific tasks for the member states. Since the Baltic States were particularly successful in the field of road safety in the last 10 years, it is certain that in the future they can do a lot in order to have the number of serious road accident victims significantly reduced and also internationally compared and assessed.
\end{abstract}

Key words: Road safety, serious injuries, MAIS3+.

\section{Introduction}

As a consequence of road accidents, the number of the seriously injured victims was over 250,000 and that of killed people was 28,000 in the EU in 2011 [1].

According to the data, on average, 44 injuries have fallen on each road accident fatality, out of which 10 injuries are considered as serious ones.

In the EU (European Union), the road accident is considered as top one death cause in the age group of 45 -year and younger ones. Road accident is similarly the cause of most hospitalizations.

Beyond human sufferings, injuries cause tremendous loss for the national economy, too. In the $\mathrm{EU}$, this is estimated to at least $2 \%$ of the GDP (gross domestic product). In 2012, this amount was up to 250 billion euros. In worldwide dimension, according to WHO (World Health Organization) data, this is approximately equal to 580 million dollars per year [2].

On the priority list, the most frequent serious

Corresponding author: Diána Sarolta Kiss, M.Sc., junior lecturer, research field: transport sciences. E-mail: kdiana@sze.hu injuries are the head and brain impairments then follow the traumas of the lower limbs and the vertebral column. Mainly vulnerable road users (pedestrians, cyclists and motorcyclists) or the most vulnerable age groups (elderly people and children) are the victims of such injuries.

Such kind of injuries can be experienced on every road types, however, most of them occur in built-up areas and their victims are the vulnerable road users. Mainly because of higher speed, injuries are even more serious outside built-up areas.

In the last period (between 2001 and 2011), the number of those who lost their lives as a consequence of road accident decreased by $43 \%$ in the $\mathrm{EU}$ countries on average, whereas that of the seriously injured by $36 \%$.

Figs. 1 and 2 illustrate the change in EU fatalities.

Comparing the two data, there are many who note that, while in the period in question in the $\mathrm{EU}$ on average, the number of fatalities decreased by $43 \%$, that of the seriously injured by $36 \%$ "only". 


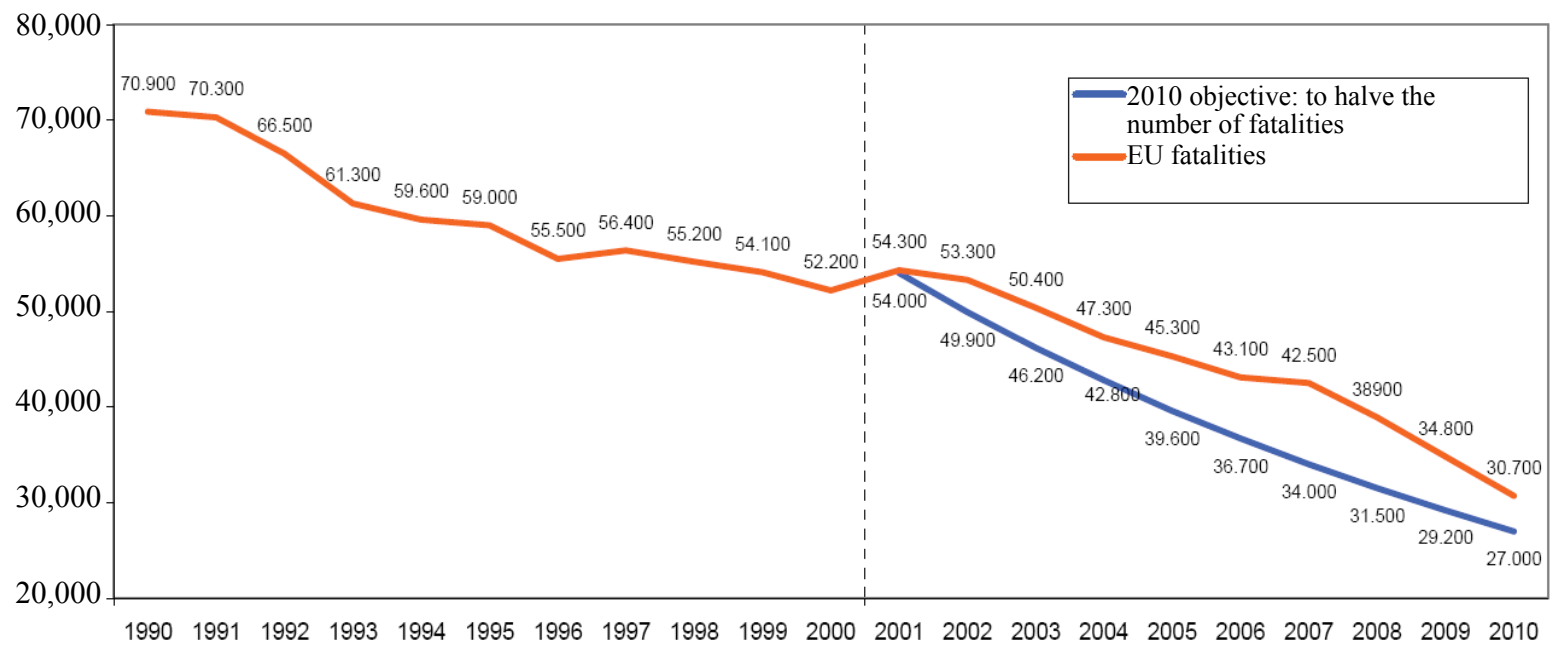

Fig. 1 The number of EU road accident fatalities between 1990 and 2010.

Source: CARE (EU accident database); national data.

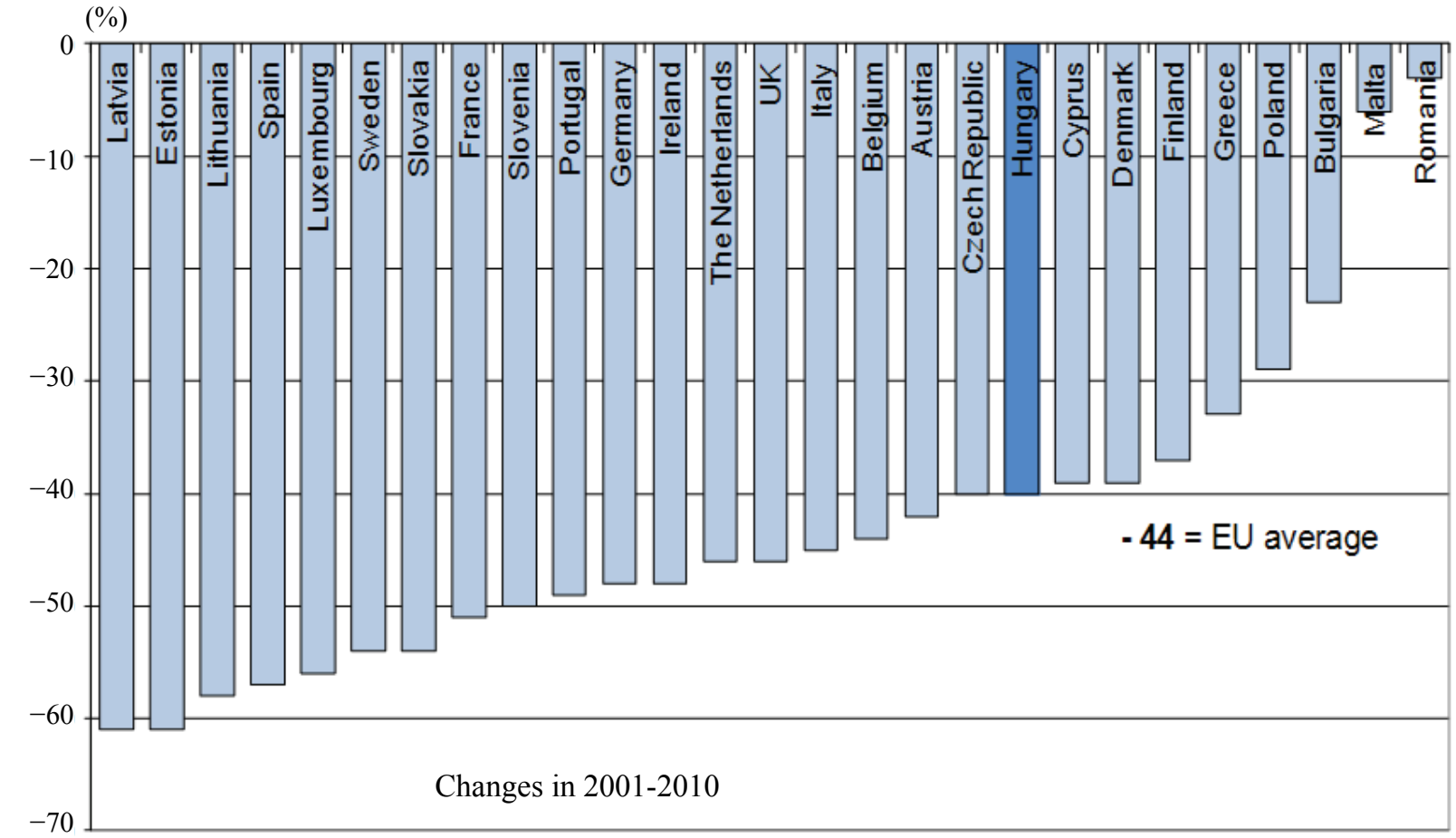

Fig. 2 Change in the number of road accident fatalities in the EU Member States between 2001 and 2010.

"Only", in our opinion, is unjustifiable because one must not forget that several passive safety devices (e.g., the safety belt, the airbag, etc.) are the cause of different kinds of injuries while saving the life of those involved in accidents.

To put it in another way, the "price" of survival mostly involves the endurance of the consequences of some injuries.
To set a more moderate, numerical target in order to change the number of seriously injured seems to be more realistic.

In most highly motorized countries, a dramatic decrease in the number of accident fatalities can be observed, i.e., primarily it was not the probability of the occurrence of road accidents with personal injury that decreased but the probability of survival increased. 


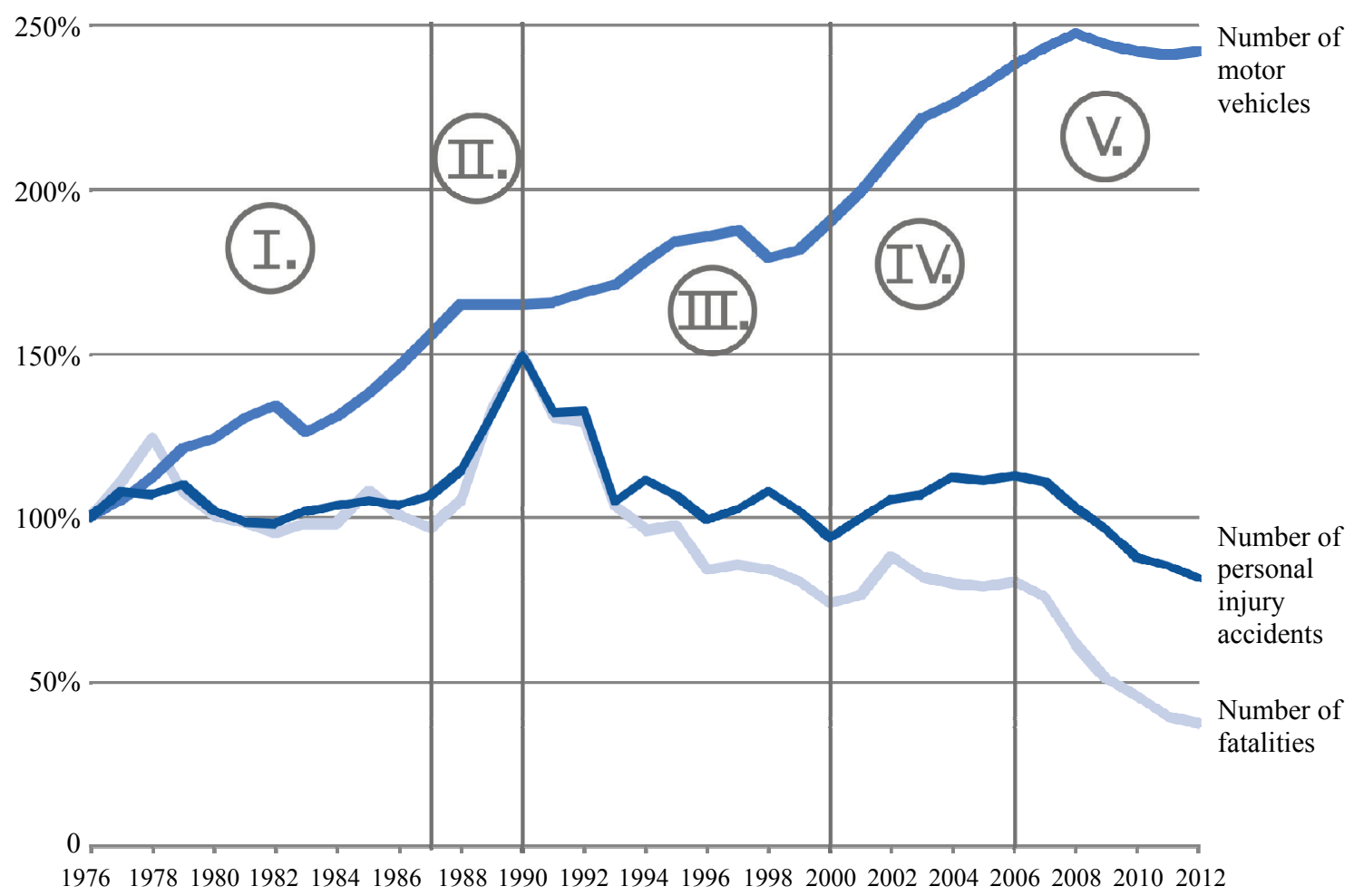

Fig. 3 Numbers of road motor vehicles, personal injury accidents and the victims killed as a consequence between 1976 and 2012 (the main road safety phases).

In other words, it seems that the development of passive safety is more effective than that of the active safety (so-called "risk compensation" is likely to have a role in this, which means that the devices meant to enhance active safety while generating a false sense of safety in the driver, unfavourably affected the driver's behaviour and leaded to higher levels of risk-taking).

Such trends can also be observed in Hungary, as shown in Fig. 3 [3]. No doubt that those active safety devices are important, too, which support accident prevention even without the driver's knowledge and support the prevention of serious injuries as a consequence as well. Such an active safety device is (for example) the ESP (electronic stability programme), which, by separate braking of different wheels, is responsible for correcting the stability loss of the vehicle (under- or over-steering) in critical situations.

\section{Definitions in Hungary}

The EU has recognized the importance of serious injuries, however, the absence of a uniform EU definition made the setting of a common quantified target impossible.

Before describing the development accomplished in this area, a brief overview of the domestic situation is given below.

Until 2011, according to national accident statistics, those injured were considered as serious cases whose recovery was beyond eight days.

The experts of accident analysis have already previously found that this 3-degree scale (fatal, serious and slight injuries) is completely improper for the appropriate classification of traumatic injuries. For example, a person who was already entirely healthy on the ninth day was considered as seriously injured as the one who was forced to end his life in a wheelchair.

The AIS (abbreviated injury scale) [4], which makes a more suitable and a more relevant comparison possible, has been used long ago in the domain of public health, nonetheless that its 
application requires high level medical knowledge.

Before dealing with this, one has to see how the tools of the accident statistics changed. As of 2011, the KSH (Hungarian Central Statistical Office) adopted the following definitions [5]. "Serious injury" means an injury suffered in the course of an accident, which:

- requires hospitalization for more than $48 \mathrm{~h}$ within seven days as of the date of the injury;

- causes some fractures, with the exception of the fractures of fingers, toes and nose;

- involves lacerations causing severe haemorrhage or nerve, muscle or tendon damages;

- causes damage to the internal organs;

- involves second or third degree burns or harms as a result of which more than $5 \%$ of the body surface area burns.

This definition, which has been introduced in the spirit of the harmonization of the different transport modes, raises doubts on the one hand, in connection with the homogeneity of time series, and on the other hand, with respect to data's verification, not to mention the fact that one cannot expect the police officer visiting the scene of the accident to judge the outcome in a professional way, since no such training has been obtained.

Despite the change in definition, no significant change appears in the decreasing tendency, so in addition to various definitions of terms, the number of injuries seems to be comparable without correction factors.

Causing a road traffic accident with serious injury is considered as a criminal offence, consequently it is the subject of a more severe judgement and the administrative proceedings related to the case differ also from the milder cases.

\section{Definitions Used in Other Countries}

It is just the absence of a uniform definition that makes the international comparison of the data related to serious injuries and the definition of the quantified EU target difficult.

This is one reason why the international comparison of road safety is still limited to comparing

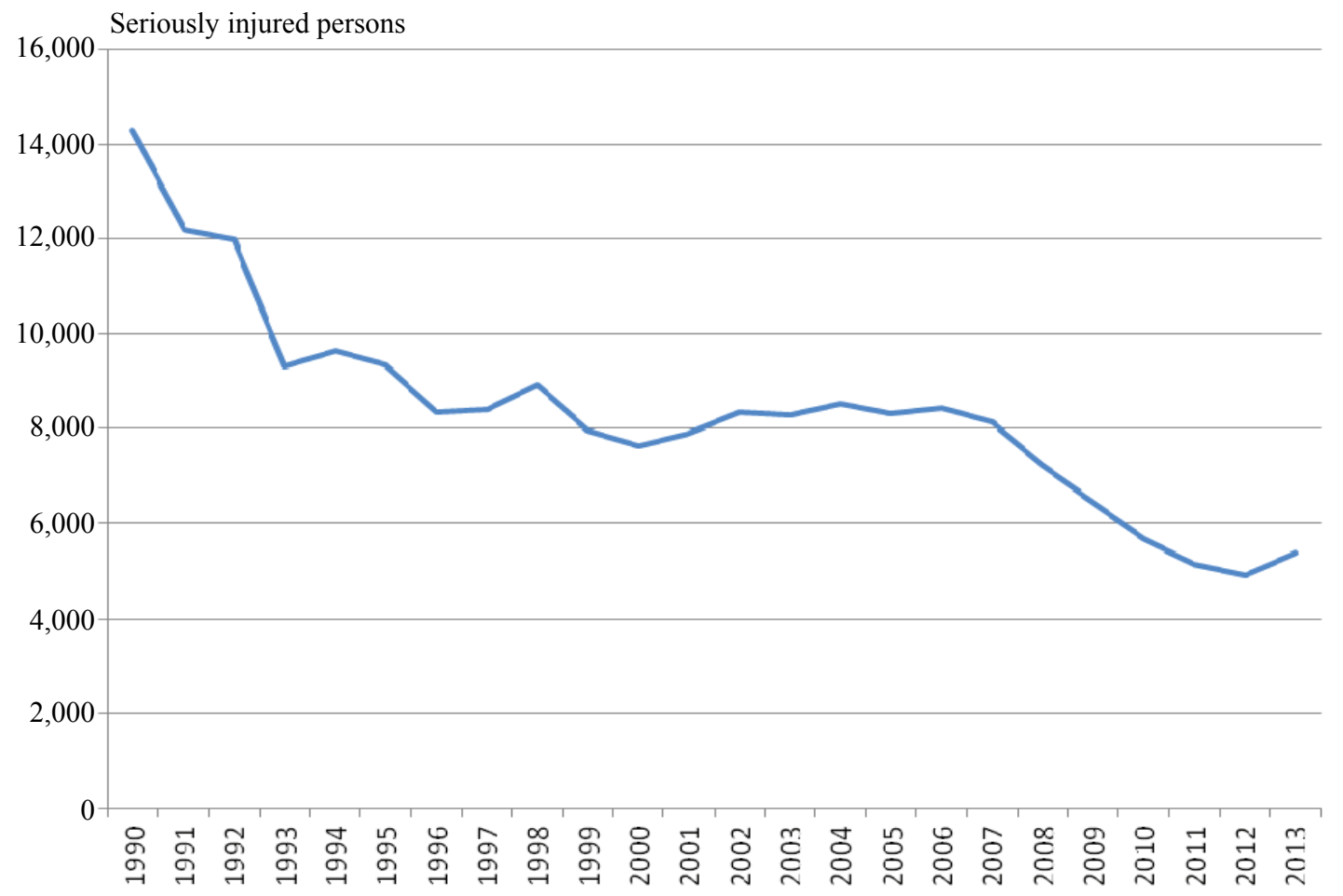

Fig. 4 Number of serious injuries resulting from road accidents between 1990 and 2013 [5]. 
the data of road accident fatalities. The definition of the fatally injured (the so-called 30-day definition) is widely uniform. In case of some countries where this is not used, its lack can be solved by the application of the so-called correction factor.

Some examples to illustrate different definitions of the seriously injured are shown:

- The period of hospitalization: $24 \mathrm{~h}$ in most countries; seven days in Poland;

- Type of injury: in Sweden, a person who has suffered some fracture, contusion, rupture, severe cut, shock, or internal injury;

- Incapacity: Austria, Switzerland;

- Time of recovery: in Japan, more than 30 days.

The comparasion of the data in different countries is further complicated by the circumstance that there is a significant discrepancy between the statistical data which are based on police investigation on the spot and the data recorded in the medical databases. This is the so-called "underreporting", which is due to the fact that, in the event of serious or slight injuries in some cases, the participants do not call the police. According to some studies, only about $70 \%$ of the data relating to serious injuries are recorded in the databases of the police [6]. From the point of view of data deficiency, the diagrams relating to fatal injuries can be considered as the most complete and reliable ones, not to mention the fact that these are the most tragic consequences of road accidents (Fig. 4).

The uniform definition could eliminate the differences manifested in data deficiency [7].

The first step taken in this direction has been made by IRTAD - the accident and traffic database of the OECD (Organisation for Economic Cooperation and Development) countries - with the introduction of the definition of the "hospitalized person". This refers to the injured who spent minimum $24 \mathrm{~h}$ in hospital [8]. Today, you may already know that, besides its benefits, it wasn't precise enough and did not really spread.

It seems that only a reliable, professional national public health database can provide a complete picture on the data relating to the injured of the road accidents.

\section{Brief Information Concerning the AIS (Abbreviated Injury Scale)}

To encode the severity of injuries, the following codes are used in the AIS 2005 [4] which was updated in 2008:

(1) Minor (slight or insignificant);

(2) Moderate;

(3) Serious;

(4) Severe (very serious);

(5) Critical (dangerous or life-threatening);

(6) Maximal (fatal or life-incompatible, currently untreatable or irrecoverable).

The common EU-wide definition until now, which has been adopted by all organizations (the EU High Level Group, IRTAD, ETSC (European Transport Safety Council), etc.), is the MAIS3+, i.e., all Grade-3 values or those beyond this according to the MAIS.

In our view, this definition is not precise enough. On one hand, it also includes the AIS-6 value, which practically means those who died on the spot. Thus, there is a risk that the fatal victims are taken into account twice. On the other hand, in engineers' opinion, the definition, which delimits the interval in question from the one side only and leaves open on the other side, is not precise.

We consider that the precise definition of serious injuries can range from MAIS3 to MAIS5. Based on the above, the EU has defined the following tasks:

- In 2014, the member states had to make arrangements for being prepared for the use of the new definition;

- In 2015, the member states have to provide information concerning the first serious injury data.

Subsequently, the EU sets a numerical target and determines a strategy for reducing the number of serious injuries between the years 2015 and 2020 .

The FERSI (Forum of European Road Safety 
Research Institutes) established a working group called the "severely injured road users in crash statistics" when recognized the challenges of the tasks and the existing gaps of the research. Dr. Péter Holló is a member of this group.

Currently, the finalization of that "position paper" is going on, which provides suggestions for the EU in order to solve the existing problems.

It's definitely worth mentioning that an ongoing EU project is just aimed at creating a uniform European system in order to record the injured persons' data in a professional and reliable way [9].

This is the JAMIE (Joint Action on Monitoring Injuries in Europe) project, which was completed by mid-2014. As we are informed that not even the suggested whole data content (FDS) will include the data describing the injury's severity. The National Health Development Institute represented Hungary in the consortium.

The EU High Level Group deems that the following solutions are feasible to resolve the outlined tasks:

- further collection of police data, application of correction factors to estimate the real number of the injured;

- collection of the data at hospitals using the MAIS codes;

- link between the two data sources (police and hospitals).

In our opinion, the first solution may only be a temporary one and the correction factors must be determined based on a representative sample. It goes without saying that data recorded by the police forming the bases of numerous activities are still very much needed (limitations are underreporting, and not always precisely defined accident circumstances). This may be the reality in the near future.

The second solution requires the establishment of the collection system of the national health data and professional application of the AIS codes. To our knowledge, this cannot be expected in the near future in Hungary. Without the collection of former police data, this is not sufficient, either.

The third option gives the optimal long-term solution providing the most complete picture about the seriously injured. In most countries, linking of the two datasets cannot be done by using the name of the injured person (protection of personality rights) which complicates this process.

Close cooperation and common work of the police and hospitals (moreover, the polyclinics and family physicians) are indispensable for preparing precise statistics.

No "medical" accomplishment can be expected from the police officer arriving at the scene of an accident to determine on the basis of what has been witnessed the severity of an injury. While having an almost permanent contact with the police, neither a doctor's working time nor the intensive stress of work allow to harmonize the number and severity of the injuries. Cooperation between these two work fields needs necessarily the development of such an information background that would allow the simple, fast but the more accurate recording.

Currently, there are only a few EU Member States that have the data meeting all the requirements (Sweden, the Netherlands, etc.).

Some countries are helped by the appropriate algorithms with the ICD (International Classification of Diseases) codes which are transformed into AIS or MAIS codes, which is also a possible solution [10].

\section{Conclusions}

The EU expectations for 2014, such as the new uniform definition, also seem somewhat premature. Some challenges which can be outlined already now are given below:

- The definition should be more precise;

- Development of a national public health database containing the severity data needs much time and expenditure. It requires the increased cooperation of the Ministry of Health and Home Affairs;

- It is not decided yet whether the overburdened 
health workers should be involved in the encoding process, or is there any other idea to solve the problem. The application requires a high level expertise. Universities and research institutes could come into question;

- The quantified target for reducing the number of seriously injured can be developed only if the real number of the occurrence of serious injuries is already known.

Overall, it may be concluded that coordinated measures are needed which have to cover the division of responsibilities, collaboration, legislation, enforcement and even many other areas.

\section{References}

[1] ETSC (European Transport Safety Council). 2013. First Milestone towards a Serious Injury Strategy. Response to the European Commission Staff Working Document. Brussel: ETSC.

[2] WHO (World Health Organization). 2014. "World Health Day: Road Safety Is No Accident!” WHO. Accessed June 5, 2014. http://www.who.int/mediacentre/news/ releases/2004/pr24/en/.

[3] Holló, P. 2014. "The Road Safety Situation in Hungary." Presented at Current Issues of the Traffic Safety-KTI-KTE Road Show 2014: "Vulnerable Road Users, Bicycle", Debrecen, Hungary. Accessed April 24,
2014. http://www.kti.hu/uploads/konferencia/KTE-KTI Roadshow_2014/3_Debrecen/1_Prof.\%20Dr.\%20Holl\% C3\%B3\%20P\%C3\%A9ter\%20-\%20A\%20k\%C3\%B6zle ked\%C3\%A9sbiztons\%C3\%A1g\%20helyzete\%20Magya rorsz $\% \mathrm{C} 3 \% \mathrm{~A} 1$ gon $\% 20$ [Kompatibilis $\% 20 \mathrm{~m} \% \mathrm{C} 3 \% \mathrm{~B} 3 \mathrm{~d}]$.p df.

[4] AAAM (Association for the Advancement of Automotive Medicine). 2008. AIS (Abbreviated Injury Scale) 2005. Chicago: AAAM.

[5] Hungarian Central Statistic Office. 2013. Traffic Accidents 2012. Budapest: Hungarian Central Statistic Office.

[6] European Commission. 2013. "Towards a European Road Safety Area: Policy Orientations on Road Safety 2011-2020 \{SEC(2010)903\}." European Commission. Accessed September 1, 2014. http://europa.eu/rapid/ press-release_MEMO-13-232 hu.htm.

[7] Broughton, J., Keigan, M., Yannis, G., Evgenikos, P., Chaziris, A., Papadimitriou, E. et al. 2010. "Estimation of the Real Number of Road Casualties in Europe." Safety Science 48: 365-71.

[8] Derriks, H. M., and Mak, P. M. 2007. Underreporting of Road Traffic Casualties. IRTAD special report.

[9] Rogmans, W. H. J. 2012. "JAMIE (Joint Action on Monitoring Injuries in Europe)." Archives of Public Health 70: 19.

[10] Bos, N. 2013. "Injury Coding Systems and Conversations between Them: AIS, ICD.” Presented at IRTAD/OISEVI Conference "Better Safety Data for Better Road Safety Outcomes", Buenos Aires, Argentina. Accessed June 5, 2014. http://internationaltransportforum.org/irtadpublic/ pdf/OISEVI-IRTAD-2013Programme.pdf. 